saturation by oximetry of emergency department patients. Respir Care 2013;57(2): 232-240.

2. Touger M, Birnbaum A, Wang J, Chou K, Pearson D, Bijur P. Performance of the RAD-57 pulse CO-oximeter compared with standard laboratory carboxyhemoglobin measurement. Ann Emerg Med 2010;56(4): 382-388.

3. Ruppel GL, Wilson HA, Gall VK, Hempkens JA. Multi-wavelength pulse oximeter is not suitable for adjusting $\mathrm{D}_{\mathrm{LCO}}$ measurements. Respir Care 2011;56(8):1115-1121.

4. O'Malley GF. Non-invasive carbon monoxide measurement is not accurate. Ann Emerg Med 2006;48(4):477-478.

5. O'Reilly M. Performance of the RAD-57 pulse co-oximeter compared with standard laboratory carboxyhemoglobin measurement. Ann Emerg Med 2010;56(4):442-444.

DOI: $10.4187 /$ respcare.02769

\section{Anxiety Disorders in Patients With COPD}

\section{To the editor:}

We read the interesting review by Willgoss and Yohannes "Anxiety Disorders in Patients With COPD: A Systemic Review."1 Willgoss et al found similarly high levels of anxiety in both in-patient and out-patient samples, and suggested that such a high incidence cannot be explained solely by the presence of an exacerbation-related hospitalization. Rather, anxiety in patients with COPD is most likely to be a chronic and disease-related phenomenon. ${ }^{1}$ Their findings also revealed the high prevalence of specific anxiety disorders, including panic disorder and phobic anxiety disorders, with panic disorder being particularly common in patients with COPD. ${ }^{1}$

However, one of the common, yet underdiagnosed, comorbidities that complicates the clinical picture of patients with COPD is the overlap syndrome: the coexistence of obstructive sleep apnea (OSA) and COPD. ${ }^{2,3}$ Lacedonia et al studied 720 patients with suspected OSA, of whom 168 had overlap syndrome, and 86 had COPD. 4 They found that the overlap syndrome group had lower daytime $\mathrm{P}_{\mathrm{aO}_{2}}$ than the OSA group, and the diurnal $\mathrm{P}_{\mathrm{aO}_{2}}$ in the overlap syndrome group correlated with age and with $\mathrm{FEV}_{1} \cdot{ }^{4}$ Overlap syndrome causes more severe nocturnal hypoxemia than either OSA or COPD alone. ${ }^{2,4}$ Therefore, overlap syndrome contributes to daytime hypoxemia and the embarrassing breathlessness, resulting in worsening anxiety and social phobia.
Furthermore, patients with overlap syndrome experience nocturnal hypoxemia, especially during rapid eye movement sleep, ${ }^{2}$ resulting in nighttime awakening, which may be associated with "sensation of suffocation or choking" and fear of death. Those episodes may carry nighttime anxiety to daytime, making anxiety a 24 hour ongoing disorder.

Clinical screening for overlap syndrome should be part of the evaluation of anxiety in patients with COPD, and that should be followed by polysomnography if warranted. ${ }^{3}$ Appropriate therapy for overlap syndrome, which may include CPAP and nocturnal oxygen, should be applied. Lack of this therapy may make other treatment modalities, such as antidepressants and psychotherapy, not as effective in reducing anxiety, panic attacks, and number of hospital admissions in patients with COPD.

Samer Alkhuja MD

Pocono Medical Center The Commonwealth Medical College East Stroudsburg, Pennsylvania

The author has disclosed no conflicts of interest.

\section{REFERENCES}

1. Willgoss TG, Yohannes AM. Anxiety disorders in patients with COPD: a systemic review. Respir Care 2013;58(5):858-866.

2. Owens RL, Malhotra A. Sleep-disordered breathing and COPD: the overlap syndrome. Respir Care 2010;55(10):1333-1344.

3. López-Acevedo MN, Torres-Palacios A, Elena Ocasio-Tascón M, Campos-Santiago Z, Rodriguez-Cintrón W. Overlap syndrome: an indication for sleep studies? A pilot study. Sleep Breath 2009;13(4):409-413.

4. Lacedonia D, Carpagnano GE, Aliani M, Sabato R, Foschino Barbaro MP, et al. Daytime $\mathrm{P}_{\mathrm{aO}_{2}}$ in OSAS, COPD and the combination of the two (overlap syndrome). Respir Med 2013;107(2):310-316.

DOI: $10.4187 /$ respcare.02716

\section{Anxiety Disorders in Patients With COPD_Reply}

\section{In reply:}

We are most grateful for Dr Alkhuja's intriguing comments on our review published in Respiratory CARE. ${ }^{1}$ He raised 2 important, inter-related questions. First, Dr Alkhuja highlights the importance of under-diagnosed comorbidities and their consequences in patients with COPD. In this context, comorbid obstructive sleep apnea (OSA) in patients with COPD, which is often described as the overlap syndrome, is under-recognized and inadequately managed in COPD patients. A recent elegant study by Mann and co-workers ${ }^{2}$ found that untreated overlap syndrome in COPD patients was associated with elevated risk of death and hospitalization due to exacerbation, compared to patients who used CPAP. Furthermore, the overlap of COPD with OSA may increase the susceptibility to arterial stiffness, which in turn predisposes to pulmonary hypertension ${ }^{3}$ and decline in cognitive function.

Second, the association of overlap syndrome with comorbid anxiety has not been fully investigated. This is partly due to the over-lapping clinical symptoms of COPD that may mask the symptoms of OSA. This requires specialized training in sleep medicine for the healthcare professionals (eg, primary care physicians and advanced practice nurses) and comprehensive assessment to detect OSA in COPD patients.

The focus of our systematic review was primarily to underscore the prevalence and the existence of a wide range of clinical anxiety disorders in patients with COPD, which are often not fully recognized and treated. Therefore, we have not explored the association between overlap syndrome and/or OSA in patients with COPD. However, we concur with Alkhuja that OSA is a disabling comorbid disease that may be a risk factor for anxiety. ${ }^{4}$ The co-occurrence of OSA in COPD patients increases the frequency of oxygen desaturation, ${ }^{4}$ defragments the quality or quantity of sleep due to hypoxemia and hypercapnia, and results in depression, somnolence, and daytime dreaming. ${ }^{5}$ All these factors contribute to COPD patients' increasing burden and worsening prognosis of anxiety symptoms and dependence on their caregivers. Hence, regular screening and monitoring for OSA and anxiety symptoms in patients with COPD is worthy of consideration. Indeed, it will be the first step to detect these disorders and refer patients to sleep centers to receive appropriate treatment.

Finally, there is a lack of robust data on the impact of overlap syndrome and the potential mechanism and its association with cardiovascular disease and COPD. Thus, further studies are required to examine the role of hypoxemia, systemic inflammation, OSA, and clinical anxiety in patients with COPD. 


\section{CorRespondence}

\section{Abebaw Mengistu Yohannes PhD \\ Department of Health Professions Research Institute Health Care for Social Change Manchester Metropolitan University Manchester, United Kingdom \\ REFERENCES}

1. Willgoss TG, Yohannes AM. Anxiety disorders in patients with COPD: a system- atic review. Respir Care 2013;58(5):858866.

2. Mann JM, Soriano JB, Carrizo SJ, Boldova A, Celli BR. Outcome in patients with chronic obstructive pulmonary disease and obstructive sleep apnoea. The overlap syndrome. Am J Respir Crit Care Med 2010; 182(7):325-331.

3. Owens RL, Malhotra A. Sleep-disordered breathing and COPD: the overlap syndrome. Respir Care 2010;55(10):13331344.
4. McNicholas WT. Chronic obstructive pulmonary disease and obstructive sleep apnoea: overlaps in pathophysiology, systemic inflammation and cardiovascular disease. Am J Respir Crit Care Med 2009;180(12):692-700.

5. Macey PM, Woo MA, Kumar R, Cross RL, Harper RM. Relationship between obstructive sleep apnoea severity and sleep, depression and anxiety symptoms in newly-diagnosed patients. PloS One 2010;5(4):e10211.

DOI: $10.4187 /$ respcare.02774 